\title{
The growing and most addressed topics in scientific articles published in the journal of basic and applied pharmaceutical sciences: a bibliometric reflection
}

\author{
Ana Carolina Kogawa ${ }^{1,2 *}$ (1) \\ 'Programa de Pós-graduação em Ciências Farmacêuticas, Controle de Qualidade, Faculdade de Farmácia, Universidade \\ Federal de Goiás (UFG), Goiânia, GO, Brasil \\ 'Laboratório de Controle de Qualidade, Faculdade de Farmácia, Universidade Federal de Goiás (UFG), Goiânia, GO, Brasil \\ *Corresponding author: carolina_kogawa@ufg.br
}

Keywords: Multidisciplinary Journal. Analytical Methods. Analytical Validation. Microbiological Evaluation. Pharmaceutical Analyses. Stability Studies. Green Analytical Chemistry.

\section{How to cite}

Kogawa AC. The growing and most addressed topics in scientific articles published in the journal of basic and applied pharmaceutical sciences: a bibliometric reflection. Rev Ciênc Farm Básica Apl. 2021;42:e747. https://doi.org/10.4322/2179-443X.0747

The topics covered in scientific articles generally follow the scope valued by the journal, which often delimits a certain area of Pharmacy. However, some journals are more extensive and cover large areas. In this sense, Journal of Basic and Applied Pharmaceutical Sciences is an example, a multidisciplinary journal, which publishes works in all fields related to Pharmaceutical Sciences.

In the last bibliometric analysis carried out with data from the Journal of Basic and Applied Pharmaceutical Sciences, from 2005 to 2021, the most published types of work were scientific articles, representing about $80 \%$ (Figure $1 \mathrm{~A}$ ). These articles are distributed in different universities, both in Brazil and in other countries, for example, Portugal, India, Spain, Cuba, Nigeria, Paraguay, Argentina, Colombia and Italy (Figure 1B). In Brazil, the articles originate from federal and state universities (Figure 1C). Among these articles, nearly 500 reported some type of funding.

In the context of the themes present in the scientific articles published in the Journal of Basic and Applied Pharmaceutical Sciences, there is a predominance of themes related to analytical methods, analytical validation and stability, microbiological evaluation, as well as topics related to the elderly people, pharmaceutical assistance, pharmaceutical care, Diabetes mellitus, medicinal plants and correct use of medications (Figure 1D). It is worth mentioning that the abstracts of these themes were the most viewed in the journal.

\footnotetext{
Financial support: School of Pharmaceutical Sciences, São Paulo State University (UNESP), São Paulo, Brazil. Conflicts of interest: The author has no financial or other potential conflict of interest.

The study was carried out at School of Pharmaceutical Sciences, São Paulo State University (UNESP), Araraquara, SP, Brazil. Received on August 06, 2021. Accepted on August 31, 2021.
} 

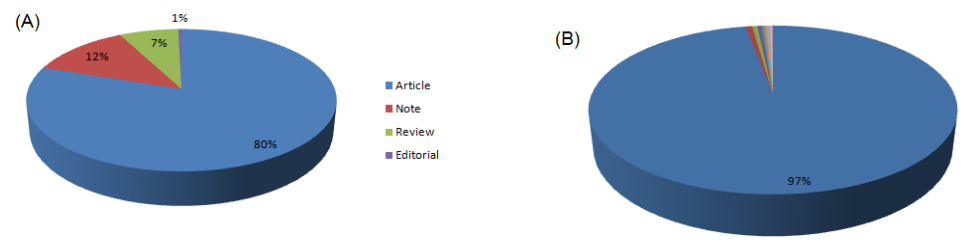

(C)

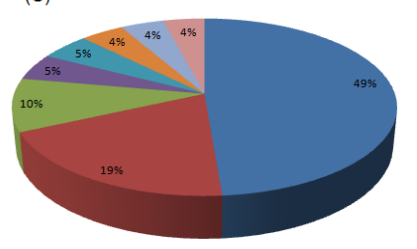

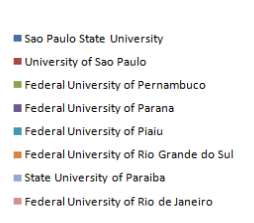

(D)

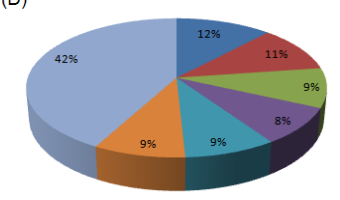

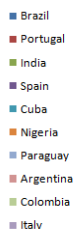

- Elderly people - Pharmaceutical assistance - Diabetes mellitus Medicinal plants

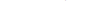
- correctuse of medications

Figure 1. Data on papers submitted to the Journal of Basic and Applied Pharmaceutical Sciences from 2005 to 2021. (A) Types of papers submitted (B) Distribution of papers among countries (C) Distribution of papers among universities (D) Types of themes submitted.

Therefore, this editorial will emphasize topics related to analytical methods for pharmaceutical analyses, since there is a demand in the literature for this type of scientific article, as shown in Figure 1D through data from articles published in the Journal of Basic Pharmaceutical Sciences and Applies in the period from 2005 to 2021, revealing that $42 \%$ of the papers submitted included pharmaceutical analyses. In the case of analytical methods, the addition of method validation to the works is intrinsic, since the method must prove valid before it can be functional. Additionally, stability studies also accompany the work on analytical methods. Another point to be considered is the division between physicochemical and microbiological methods, which makes the subject of analytical methods broader and more diversified.

From the articles published in the Journal of Basic Pharmaceutical Sciences and Applies from 2005 to 2021, the most popular topics (Figure 1D) address activities related to Quality Control, Analytical Development, Product Development and Production Process of industrial chemical-pharmaceutical sectors. This demand can be explained by the desire for continuous improvement of analytical methods, which currently value speed, specificity and sustainability. Since Paul Anastas and John Warner, in the 1990s, postulated the 12 principles of Green Chemistry and later the principles of Green Analytical Chemistry, the scientific community has awakened to multidisciplinary concerns involving the environmental impact of analytical decisions, waste generation and operator health, for example ${ }^{1-6}$.

Thus, topics involving analytical methods (physicochemical and microbiological), and which bring issues such as analytical validation and stability, will be constantly required, since they will be constantly being updated according to the demand of current pharmaceutical analyses.

\section{ACKNOWLEDGMENTS}

The author is immensely grateful to ROSA CAMILA LUCCHETTA, Pharm, MSc, PhD, for her contribution to the elaboration of this Editorial.

CONFLICT OF INTERESTS

The author has no financial or other potential conflict of interest.

\section{REFERENCES}

1. Marco BA, Rechelo BS, Totoli EG, Kogawa AC, Salgado HRN. Evolution of green chemistry and its multidimensional impacts: A review. Saudi Pharm J. 2019;27(1):1-8.

http://dx.doi.org/10.1016/j.jsps.2018.07.011. PMid:30627046.

2. Kogawa AC, Salgado HRN. Golden age of green chemistry. EC Microbiol. 2017;12:52-4.

3. Kogawa AC, Salgado HRN. Analytical methods: where do we stand in the current environmental scenario? EC Microbiol. 2017;13:102-4. 
4. Kogawa K, Carolina A, Salgado S, Nunes HR. Analytical methods need optimization to get innovative and continuous processes for future pharmaceuticals. Sch Acad J Pharm. 2016;5(6):240-4. http://dx.doi.org/10.21276/sajp.2016.5.6.3.

5. Gałuszka A, Migaszewski Z, Namieśnik J. The 12 principles of green analytical chemistry and the significance mnemonic of green analytical practices. Trends Analyt Chem. 2013;50:78-84. http://dx.doi.org/10.1016/j.trac.2013.04.010.

6. Anastas PT. Green Chemistry and the role of analytical methodology development. Crit Rev Anal Chem. 1999;29(3):167-75. http://dx.doi.org/10.1080/10408349891199356. 